\title{
Analyzing Temporal Patterns of Groups and Individuals in an Online Learning Forum
}

\author{
http://dx.doi.org/10.3991/ijet.v10i5.4722 \\ Mengmeng Cheng, ChienYuan Su, Jianping Zhang and Yuhui Yang \\ Zhejiang University, Hangzhou, China
}

\begin{abstract}
Time plays a fundamental role that benefits and challenges online discussions. It requires considering the temporal aspect for both analyzing how learning takes places through online discussion and for designing effective structures to support discussion activity. The purpose of this study was to examine the temporal patterns of group and individual participation in a discussion forum. Data were collected from the logs and postings of college students. This study first investigated the temporal patterns of group participation in the discussion forum and then analyzed how promptness and initiative of individuals in online discussion related to their grades at the end of the semester. Results revealed that students posted mainly in the first 23 days and at the deadline. Students preferred discussing something related to the course content with others as soon as possible after they learned. They were willing to post in the morning and evening. There was strong relationship between students' promptness and initiative in the online discussions and their grades. Reasons for these results are discussed.
\end{abstract}

Index Terms-discussion forum, temporal pattern, pace, sequence

\section{INTRODUCTION}

Online discussion deals with the time and space restrictions that occur in traditional class. It has been widely used to support interaction between students in online courses. It allows students to seek help, offer advice, and receive others' perceptions by reading and responding to postings [1]. The asynchronous nature of online discussion provides the flexibility of the temporal scale or duration of an activity $[2,3]$. Students could take as much time as they needed to reflect on the others' perceptions and to contribute their own ideas in responses at their own convenience [4]. That means students could compose thoughts at their own speed rather than rushing to comment before others move on [5].The asynchrony of online discussion, which refers to communication across "delayed time" [6], also presents challenges to meaningful conversation. For example, students must $\log$ in to the discussion forum repeatedly and wait for unknown and variable amounts of time for responses to their comments [7]. Longer response times can inhibit students' expectations and need for acknowledgement [8].

Time plays a fundamental role that benefits and challenges online discussions. Effective online discussion requires considering the temporal factors of discussion activity [9]. Understanding students' participation patterns in the online discussion forum from a temporal perspective could enhance explanatory power, support discussion progress, and facilitate student learning. Teachers could utilize this temporal knowledge to choose appropriate timeframes to build discussion activities or monitor discussions in real-time to decide when a new discussion topic is needed. The exploration of the temporal patterns would also suggest alternative ways to anticipate and design discussion intervals and environments to promote higher levels of discussion. Despite the importance placed on the temporal concept, existing research does not fully utilize the temporal information of the discussion process [3,10,11,12]. As Peters and Hewitt (2010) said, "Little is known about the moment-to-moment behaviors of students as they participate in asynchronous discussions" [7]. Few studies have explored the temporal characters of online discussions. The aim of this study was to investigate the participation patterns of groups and individuals from temporal perspectives.

To investigate the temporal characteristics of online discussions, the attribute of time needs to be analyzed. Temporal concept can be considered both absolutely and relatively, and it can be examined for constancy, regular change or irregular change over time [13]. Temporal patterns can expose important aspects of group and individual discussion processes. It is often analyzed by applied temporal indicators of frequency $[14,15,16]$, continuous flow [17,18], duration [19], and lag time, pace and sequence [20]. Pace and sequence are two main indicators to represent the historical progress of community students or how discussions progress over time [21].

Pace relates to the rate at which events occur over time [22]. Pace is to examine the rhythm of discussions as groups engage in the forum over time, which invites consideration of the concept of the density or dispersion of discussion activities. The flexibility to participate in the discussion over a prolonged period means that postings are often temporally dispersed; it may condense in intense bursts or distribute it slowly across time. Students have a high degree of autonomy that not only decides the duration they are involved in the discussion, but also controls their pace of when and how often this occurs [9]. While this benefits students being able to express individual ideas, it could also impose pressure for students to keep up with the discussion's momentum [9,23]. Haythornthwaite and Gruzd (2012) examined posting patterns of graduate students' participation in a series of weekly reading-based discussions across eight iterations. They found that in a semester-long rhythm that resembled an arc, participation rose across weekly discussions from the start of class to mid-semester and then declined again toward the end [24]. There was a similar trend in relation to the study by Dringus (2010). Based on 2,500 postings contributed by 113 students, Dringus found that the momentum of forum discussion may be short-term, between 21 and 28 days, and appears to decline rapidly after 31 days. Students 
posted mainly early to mid-week and less on the weekend [3].

Sequence refers to the order and patterns of successive events [22]. Sequence is another aspect to estimate the level of participation. It examines the promptness and initiative of the individual student to participate in thread discussions timely [25]. The relationship between participation in the discussion forum and student grades is a very fertile topic for research. Previous research has shown that participation, measured as interaction with peers and teachers, has a positive effect on grades (e.g., Fredericksen, Picket, Shea, Pelz, \& Swan, 2000; Hiltz, Coppola, Rotter, Turoff, \& Benbunan-Fich, 2000) [26]. Davies and Graff (2005) examined the relationship between the level of online participation and grades indicated that students who failed in one or more modules interacted less frequently than students who achieved passing grades [27]. Swan et al.'s (2000) study revealed that students who rated their level of interaction with classmates as high also reported significantly higher levels of learning [28]. Similarly, Picciano found a correlation between the number of student discussion postings in a course and performance on exams; students had greater quality and quantity of learning as a result of participating in the discussions. However, this correlation was not statistically significant [29]. The beneficial effects of asynchronous discussions have been discussed. In contrast, Davies and Graff examined the frequency of the online interactions of undergraduates compared with their grades at the end of the year. The findings revealed that greater online interaction did not lead to significantly higher performance; however, students who failed in their courses tended to interact less frequently [27]. Unfortunately, few online discussion participation-related studies explored another attribute of participation: sequence and its relation with grades.

The aim of the present study was to investigate the participation patterns of groups and individuals. As Eastmond (1995) argued, computer-mediated communication was not inherently interactive, but depended on the frequency, timeliness, and nature of the posted messages [30]. In this study, we were interested in the temporal analyses of participation patterns. In particular, we were interested in quantifying the relation between the student's grade and the way she or he engaged with the discussion forum. The study sought to answer the following research questions:

- Question 1: what is the group participation pattern in the online discussion from a temporal perspective?

- Question 2: how do promptness and initiative of online discussion relate to student grades?

The participants of this study were undergraduate students $(\mathrm{N}=32)$ from Zhejiang University of China, consisting of 18 females and 14 males and ranging from 19 to 21 years in age. They majored in pedagogy and public service administration. The students registered for the hybrid learning course, "Information Technology and Teaching" ( 2 credits) an eight-weeks-long open course, in the 2014 summer semester at Zhejiang University. It met twice a week and was jointly organized by eight facilitators (3 teachers, 3 assistants and 2 technicians).

The hybrid course offered both online courses and faceto-face lectures. For face-to-face lectures, the teachers focused on problems students confused. For the online part, the students logged into the course platform to learn and do the assignments (unit quiz and cooperative activi- ties) each week. Students also discussed one or two topics that had the same discussion forum structure without contribution limits; see Figure 1. Students were not required to make a particular number of postings to the discussion board each week. However, students were informed that part of the grade for the course would be based on their participation in these discussions.

The first two topics were covered in the first week. After a full discussion was completed and there were no more student posts, topic 3 was released. Topic 3 was made in the fourth week. Topic 4 and topic 5 were released in the fifth week. Topic 6 and topic 7 were made in the sixth week. Topic 8 was released in the seventh week. Once initiated by the teachers, all topics were open for discussion for the remainder of the term.

The course platform, which was provided by Educational Technology Institute in Tsinghua University, kept an account of the moment-to-moment behaviors of the students in the whole process, including the date and time of the posting, posting sequence, identifier of the message poster, activity, interaction, and quiz results.

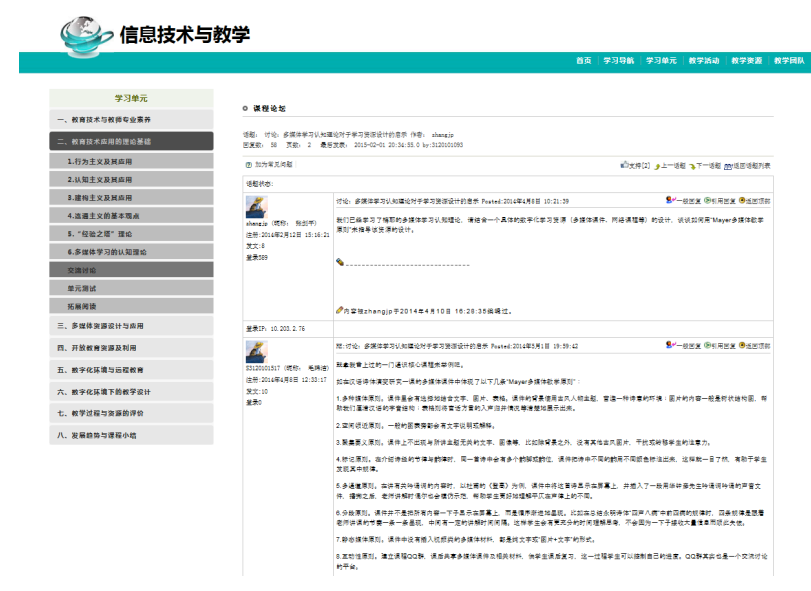

Figure 1. The discussion forum of "Information Technology and Teaching" course

\section{INSTRUMENTS}

This study first investigated the participation pattern by conducting a temporal analysis of the group participation in the discussion forum. It was based on descriptive statistics of the postings in a hybrid learning course offered by Zhejiang University. The vitality of the topics and the number of postings were calculated. And then the Chisquare test was conducted to determine if the number of postings on the day of the week and the time of the day produced a statistical difference.

The study revealed the promptness and initiatives in the online discussions among the 32 undergraduates. Correlation analysis was conducted with students' final grades and their sequence of 8 topics in the discussion forum. This part of the study was not to predict a student's grade from her activity but to get insight into how high grade or low grade students distributed their activities across the discussion forum.

\section{RESULT ANALYSIS}

The discussion transcripts were analyzed for the 8 topics, containing 237 postings. Figure 2 gives the distribution of the postings across the term. The first topic had 
SHORT PAPER

ANALYZING TEMPORAL PATTERNS OF GROUPS AND INDIVIDUALS IN AN ONLINE LEARNING FORUM
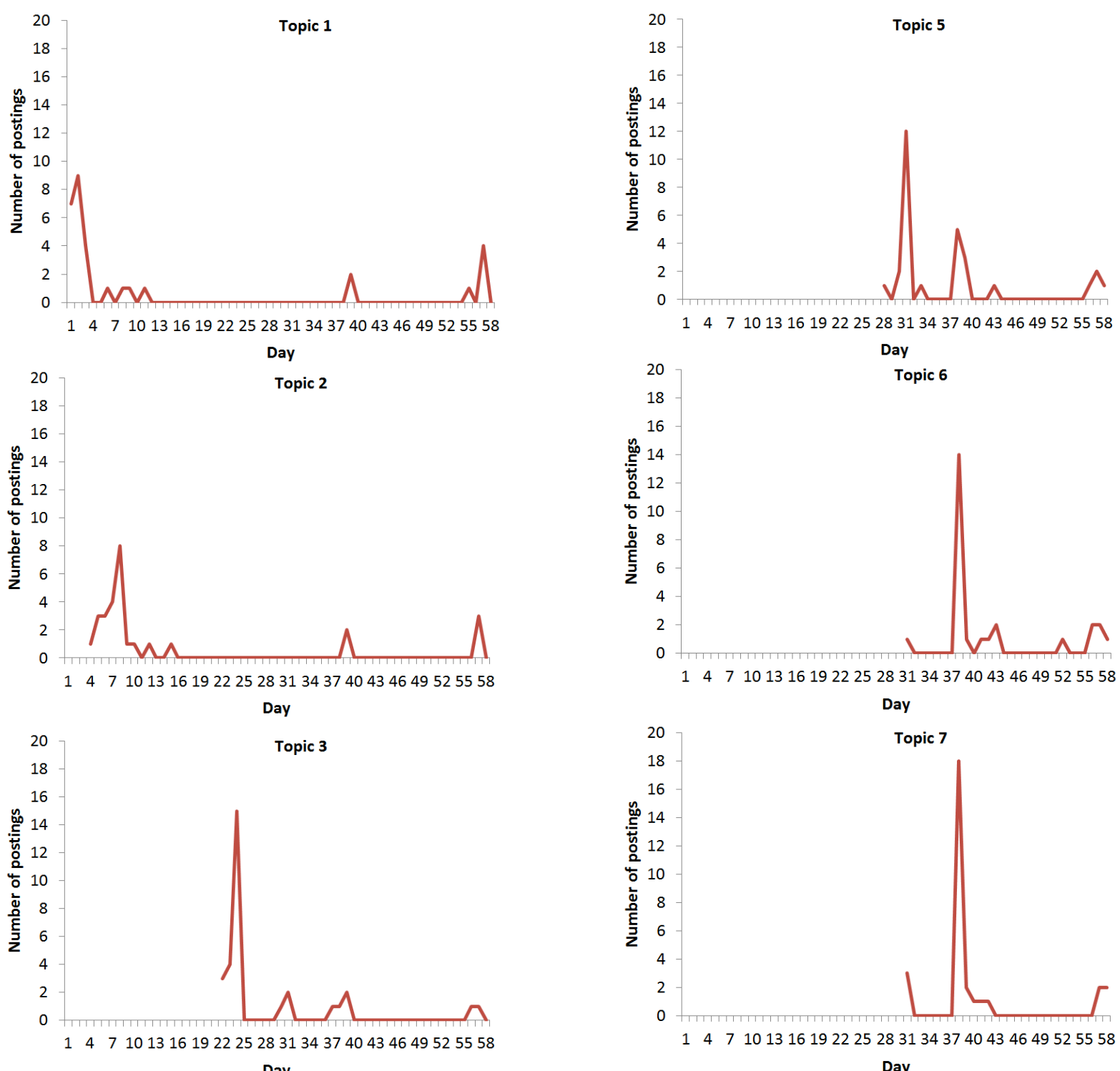

Day
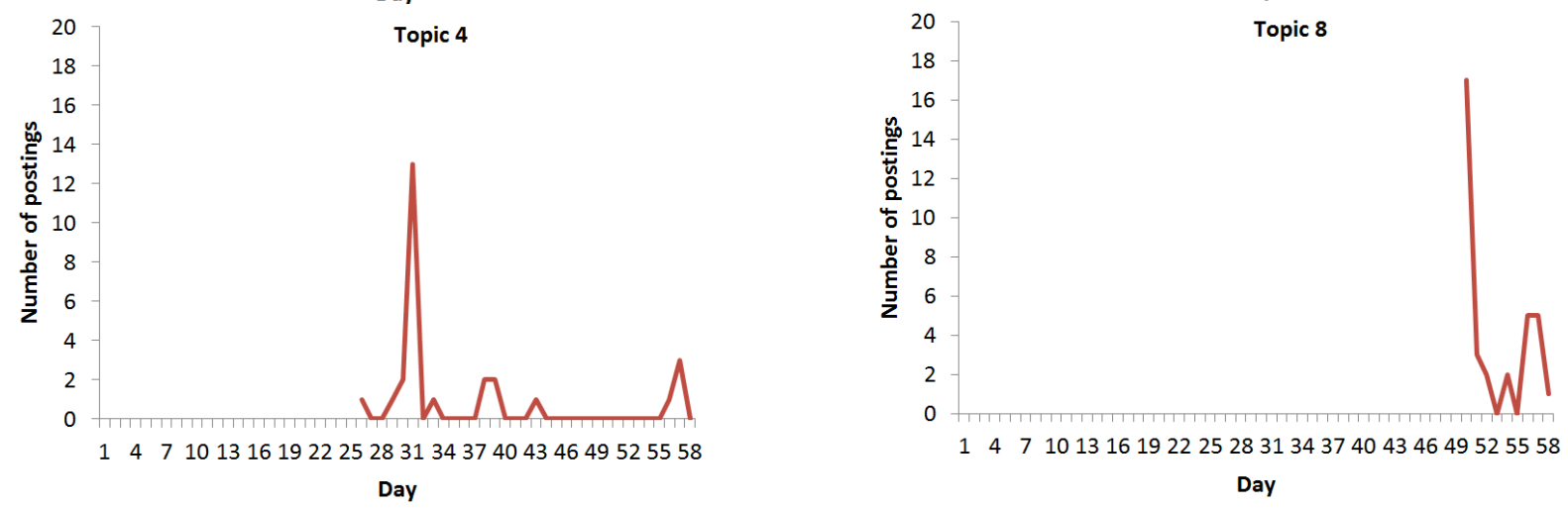

Figure 2. The distribution of postings across the term

arrangements across the 58-days term. Topic 2 was 55 days in duration. Topic 3 was 37 days. Topic 4 accounted for 33 days, and topic 5 accounted for 31 days. Topic 6 and topic 7 had arrangements across 28 days. Topic 8 had a 9-day term.

There were different durations but a familiar tendency in the 8 topics. Most postings were made in the first few days, and then there was a sharp decline. Most of the time there was a lull. In the last days, there was a growth, see Figure 2. Topic 8 did not get a full discussion; therefore, the other 7 topics were calculated. The majority of the postings $(84 \%)$ were posted within 1 to 14 or 15 days (two weeks) in the thread; $90 \%$ of the postings were made in the first 23 days. A postings rate in the last 3 days reached $13.66 \%$. Discussion reached the peak at 2 to 8 days from the first posting. 
Making comparisons about the pace of postings over the seven days of the week with an expected distribution of the average number of posting for each of the weekdays (33.86 postings), the Chi-square test produced an $\chi^{2}$ of $190.279, \mathrm{df}=6, \mathrm{p}<0.001$. More postings occurred between the start of the week and mid-week, Mondays (64 postings), Tuesday (29 postings) and Wednesday (94 postings). And then there was a sharp decline, Thursday (16 postings), Friday (10 postings), Saturday ( 7 postings) and Sunday (17 postings). With regard to the certain time of the day $(0: 00$ to $6: 00,6: 00$ to $12: 00,12: 00$ to $18: 00,18: 00$ to $24: 00$ ), the average number of postings for each of the time was 59.25, and the Chi-square test produced an $\chi^{2}$ of 115.624 , df $=3, p<0.001$. The data revealed that a higher incident of the number of day hours followed by 6:00 to $12: 00$ (119 postings), $18: 00$ to $24: 00$ (74 postings), $12: 00$ to 18:00 (34 postings) and 0:00 to 6:00 (10 postings). The results indicated that the pace of postings does vary to a statistically significant extent by day of week and time of day.

Correlation analysis was conducted on the students' final grade and the sequence of the 8 threads in the discussion forum. Sequence in the discussion forum was to plot the student's average forum activity level as a function of her position in the thread - that was, let $\mathrm{f}(\mathrm{j})$ was the lifetime number of the forum contributions of the student in position $\mathrm{j}$ in the thread, averaged over all threads. The average position of each student in the 8 threads was calculated.

With regard to final grade distribution, students on campus had scores from the two parts: studying in class and online. First, we examined the overall final grade distribution in the class. After eight weeks of learning and assessment, scores of 90-100 accounted for $21.88 \%$; 80-89 accounted for $53.13 \%$; 70-79 accounted for $18.75 \%$; 60 69 accounted for $3.13 \%$; and below 60 accounted for $3.13 \%$. There were 32 learners enrolled in this course; 31 learners passed the course and 1 learner dropped out. Let $g$ (j) be the final course grade of the student in position $\mathrm{j}$ in the thread, averaged over all threads.

In performing a correlation on student final grades with the average position in the discussion forum, the results were negative at 0.710 , statistically significant $(0.00025$ level). The overall conclusion was that students' promptness and initiative, as measured by the sequence in the discussion forum, did have a relationship to students' final grades of the course.

\section{DISCUSSION}

\section{A. What is group participation pattern in an online discussion from a temporal perspective?}

The forum was organized in a sequence of postings: each topic started with an initial posting from teachers that was then followed by a sequence of further postings. In this study, whether the duration was long or short, there was a familiar pace pattern: a peak in the first few days and then the posting number gradually declined. Some small peaks followed. In the last few days, there was often a sharp increase (see Figure 2). This study did not attempt to answer the "why?" for this phenomenon, but speculation is possible.

Research has consistently found that messages posted early in a discussion term got more replies than those posted later [2,9]. Hewitt and Teplovs (1999) found that responses within 24 hours resulted in a 0.63 probability of eliciting a reply. And then the possibilities of replies dropped to 0.41 and 0.31 , respectively, after 1 and 2 days [8]. As time goes by, fewer and less meaningful postings were contributed to the discussion, so the conversation did not attract onlookers and make them post. That would trigger a pattern of a decreased cycle. Wise, Zhao, and Hausknecht found that the pacing of participation across a discussion or the term can vary based on interest in the topic as well as the class and personal schedules [9]. One explanation for this pattern may be that interest in the discussion was gradually fading as time passed by if there were no more contributors join the discussion.

On one side, because of the discussions' asynchronous nature, the discussion could stretch across days, weeks and months [6]. Students might log in repeatedly and wait for an undetermined amount of time for a reply. Too much lag-time could lead to decay of the individual and collective memory of the recent interactions. Students need to re-situate themselves in the discussion by rereading and rethinking prior postings and to rework their ideas and others' for a deeper reflection [31]. The cognitive challenges of rethinking and reworking the discussion may inhibit students' expectations and need for acknowledgement, potentially leading them out of the discussion and reducing the discussion momentum [3]. That would run the risk of contributing postings that are redundant or dissociated with the prior discussion to lead to thread decay and death [32].

On the other hand, the loss of interest may be related to competition between threads. New threads may cause students to lose interest in old ones. In the online discussion, students may simultaneously face the cognitive overload of monitoring and participating in multiple concurrent discussion threads. Postings contributed late in the discussion must compete for attention against a larger number of postings. The decreases in response probabilities were caused by the progressive increase of concurrent threads and messages competing for the students' responses [8,32].

With regard to the class and personal schedules, the result was consistent with the findings by Gibbs et al. (2008). Students preferred post in the morning (6:00 to 12:00) and in the evening (18:00 to 24:00). There were fewer lessons in the evening, and students usually liked to work in the morning. Few students posted after midnight (0:00 to 6:00). Forum posting was highest for Monday and Wednesday. Students had the course on Monday and Wednesday, and the topic was related to the content of course. They preferred discussing the something related to the course content as soon as possible after they learned. Friday and Saturday were the days with the least participant activity. There was an increase on Sundays; maybe students were aware of the time, having class on Monday, and then they checked and posted in the forum.

Deadline was a factor that can explain the sharp increase, which had a concentrated distribution in the last few days. Jeong and Frazier (2008), Dringus and Ellis(2010) also found the phenomenon that the number of replies was higher on the last day $[3,19]$. The content of the postings were almost always 'I agree with them' or something uncorrelated. 
Deadline had a clear effect both on when students participated in the discussion and to what degree the discussion developed into an actual discussion [9]. Deadline was used to keep students moving at a particular pace and to meet the possible self-paced needs of the students [9]. Jeong and Frazier (2008) recommended that teachers should establish deadlines and hold discussions over longer periods. It may give students an opportunity to arrange their own time for participation rather than rushing to post by a certain day. However, if a deadline for posting was established, notable spikes in intensity and density were likely to occur on those days [9]. Some students may have logged in at the last minutes and tended to be shallow in their presentation of thinking; hence most late postings did not lead to an increase in responses, and consequently no further discussion. The flurry of postings right before the deadlines was due to interest in receiving the corresponding grade [33]. Students failed to achieve a deep reflection when pressured to adhere to deadlines [34]. Establishing a deadline may not be a valuable strategy if students are merely posting at the deadline. Teachers may inform students that late postings or postings right before the deadline will not count toward their performance unless the late posting actually contributes something valuable to the discussion or arouses a meaningful response-to-response [35]. That may help avoid the intensity of spikes in the late days.

The 8 threads ranged from 58 to 9 days. The duration of topic 1 and topic 2 was too long, so there was a long silent period. In this study, we could see that a longer period would not increase the number of postings in the discussion forum. It may be not be meaningful to run a discussion beyond a certain number of days. The duration of the last topic (9 days) was not sufficient for students to deliberate and have deeper reflection. A too short period (Topic 8) may not give students enough time to contribute meaningful postings or to reflect to the full extent on the discussion. High quality responses or deeper reflection needs enough time and proper duration. As shown in Figure 2, $84 \%$ of the postings were made by the $15^{\text {th }}$ day, and $90 \%$ by the $23^{\text {rd }}$ day. Teachers should pay more attention in the first 23 days, especially for the first two weeks from the first postings.

\section{B. How promptness and initiative of online discussion relates to student grades?}

There was a reflection of this distinction between the earlier and later contributors regarding the grades. The earlier contributors of a topic tended to have a higher grade than the later contributors to the topic; students who failed in the courses tended to be later contributors or never posted in the forum. The results of this study supported that students who had higher promptness and initiative tended to have higher grades, while students who had the lower promptness and initiative tended to have lower grades. Promptness and initiatives demonstrate selfmotivation and permit commentary on whether or not the student is actively and consistently engaging in the discussion forum. In this study, there is moderate support to suggest that the promptness and initiative in the discussion is a significant factor in distinguishing between individuals who pass or fail the course. This suggests that we maybe observing a dynamic that students who have high grades are more prompt and take initiative in the class by joining the threads teachers initiate.

\section{CONCLUSION}

In this paper we took some initial steps to characterize the ways in which students engaged with the online discussion forum. It explored learning as progress over a discussion's life-span. An attempt was made to determine the temporal patterns of groups and individuals. The study revealed that students posted mainly in the first 23 days and around deadlines. Students preferred discussing the something related to the course content as soon as possible after they learned. They were willing to post in the morning and evening. Groups' progress was triggered by members' awareness of time, their schedule, and deadlines. There was strong relationship between students' promptness and initiative in online discussions and their grades.

Limitations of these findings included the study's sample size as well as the structures and settings of a discussion activity. Due to the small number of participants, these data were not necessarily representative of interactions among students in different groups or classes. The analysis of transcript data depended on the researchers' qualitative estimate of pace.

\section{ACKNOWLEDGMENT}

In this work, the web-based learning platform and corresponding technical support was provided by the Institute of Education Technology in Tsinghua University. Here, we would like to express our heartfelt gratitude to Professor JianGang Cheng, XiBin Han and their teams.

\section{REFERENCES}

[1] S. M. Nielsen, "Half bricks and half clicksl: Is blended onsite and online teaching and learning the best of both worlds?" In M. S. Plakhotnik, \& S. M. Nielsen (Eds.), The Seventh Annual College of Education Research Conference: Urban and International Education Section. Presented at the COERC 2008, Miami, Florida USA: Florida International University, pp. 105-110, 2008.

[2] J. B. Pena-Shaff and C. Nicholls, "Analyzing student interactions and meaning construction in computer bulletin board discussions," Computers \& Education, vol. 42, pp. 243-265, 2004. http://dx.doi.org/10.1016/j.compedu.2003.08.003

[3] L. P. Dringus and T. Ellis, "Temporal transitions in participation flow in an asynchronous discussion forum," Computers \& Education, vol. 54, pp. 340-349, 2010. http://dx.doi.org/10.1016/ j.compedu.2009.08.011

[4] L. Harasim, "Shift happens: Online education as a new paradigm in learning," The Internet and higher education, vol. 3, pp. 41-61, 2000. http://dx.doi.org/10.1016/S1096-7516(00)00032-4

[5] G. E. Prestera and L. A. Moller, "Exploiting Opportunities for Knowledge-Building in Asynchronous Distance Learning Environments.," Quarterly Review of Distance Education, vol. 2, pp. 93-104, 2001.

[6] B. Christie, "Electronic meetings". In B. Christie (Ed.), Human factors of information technology in the office: Chichester, England: Wiley \& Sons, Inc., pp. 97-144, 1985.

[7] V. L. Peters and J. Hewitt, "An investigation of student practices in asynchronous computer conferencing courses," Computers \& Education, vol. 54, pp. 951-961, 2010. http://dx.doi.org/10.1016/ j.compedu.2009.09.030

[8] J. Hewitt and C. Teplovs, "An analysis of growth patterns in computer conferencing threads," in Proceedings of the 1999 conference on computer support for collaborative learning, 1999, $\mathrm{p}$. 29. http://dx.doi.org/10.3115/1150240.1150269

[9] A. F. Wise, Y. Zhao, S. Hausknecht, and M. M. Chiu, "Temporal Considerations in Analyzing and Designing Online Discussions in Education: Examining Duration, Sequence," Assessment and evaluation of time factors in online teaching and learning, p. 198, 2013.

[10] A. F. Wise, N. Perera, Y. Hsiao, J. Speer, and F. Marbouti, "Microanalytic case studies of individual participation patterns in an 


\section{SHORT PAPER}

\section{ANALYZING TEMPORAL PATTERNS OF GROUPS AND INDIVIDUALS IN AN ONLINE LEARNING FORUM}

asynchronous online discussion in an undergraduate blended course," The Internet and Higher Education, vol. 15, pp. 108117, 2012. http://dx.doi.org/10.1016/j.iheduc.2011.11.007

[11] A. Jeong, "A guide to analyzing message-response sequences and group interaction patterns in computer-mediated communication," Distance education, vol. 26, pp. 367-383, 2005. http://dx.doi.org/10.1080/01587910500291470

[12] A. F. Wise and M. M. Chiu, "Analyzing temporal patterns of knowledge construction in a role-based online discussion," International Journal of Computer-Supported Collaborative Learning, vol. 6, pp. 445-470, 2011. http://dx.doi.org/10.1007/s11412-0119120-1

[13] G. Dyke, R. Kumar, H. Ai, and C. P. Rosé, "Challenging assumptions: Using sliding window visualizations to reveal time-based irregularities in CSCL processes," in Proceedings of the 10th International Conference of the Learning Sciences, 2012, pp. 363370 ..

[14] K. Burnett, L. J. Bonnici, S. D. Miksa, and J. Kim, "Frequency, intensity and topicality in online learning: An exploration of the interaction dimensions that contribute to student satisfaction in online learning," Journal of Education for Library and Information Science, pp. 21-35, 2007.

[15] W. Gibbs, L. D. Simpson and R. S. Bernas, "An analysis of temporal norms in online discussions," International Journal of Instructional Media, vol. 35, p. 63, 2008.

[16] K. Swan and P. Shea, "The development of virtual learning communities," Learning together online: Research on asynchronous learning networks, pp. 239-260, 2005.

[17] B. J. Zimmerman, "Becoming a self-regulated learner: An overview," Theory into practice, vol. 41, pp. 64-70, 2002. http://dx.doi.org/10.1207/s15430421tip4102 2

[18] S. Järvelä and A. F. Hadwin, "New frontiers: Regulating learning in CSCL," Educational Psychologist, vol. 48, pp. 25-39, 2013. http://dx.doi.org/10.1080/00461520.2012.748006

[19] A. Jeong and S. Frazier, "How day of posting affects level of critical discourse in asynchronous discussions and computer $\square$ supported collaborative argumentation," British Journal of Educational Technology, vol. 39, pp. 875-887, 2008. http://dx.doi.org/10.1111/j.1467-8535.2007.00789.x

[20] C. B. Cazden and S. W. Beck, "Classroom discourse," Handbook of discourse processes, pp. 165-197, 2003.

[21] A. F. Wise, Y. Zhao and S. N. Hausknecht, "Learning analytics for online discussions: a pedagogical model for intervention with embedded and extracted analytics," in Proceedings of the Third International Conference on Learning Analytics and Knowledge, 2013, pp. 48-56. http://dx.doi.org/10.1145/2460296.2460308

[22] B. W. Hesse, C. M. Werner and I. Altman, "Temporal aspects of computer-mediated communication," Computers in Human Behavior, vol. 4, pp. 147-165, 1988. http://dx.doi.org/10.1016/07475632(88)90023-4

[23] M. Gabriel, "Learning Together: Exploring Group Interactions Online.," Journal of distance education, vol. 19, pp. 54-72, 2004..

[24] C. Haythornthwaite and A. Gruzd, "Exploring patterns and configurations in networked learning texts," in System Science (HICSS), 2012 45th Hawaii International Conference on, 2012, pp. 3358-3367. http://dx.doi.org/10.1109/hicss.2012.268

[25] S. Edelstein and J. Edwards, "If you build it, they will come: Building learning communities through threaded discussions," Online Journal of Distance Learning Administration, vol. 5, 2002.

[26] S. Hrastinski, "What is online learner participation? A literature review," Computers \& Education, vol. 51, pp. 1755-1765, 2008. http://dx.doi.org/10.1016/j.compedu.2008.05.005

[27] J. Davies and M. Graff, "Performance in e-learning: online participation and student grades," British Journal of Educational Technology, vol. 36, pp. 657-663, 2005. http://dx.doi.org/10.1111/ j.1467-8535.2005.00542.x

[28] K. Swan, P. Shea, E. Fredericksen, A. Pickett, W. Pelz, and G. Maher, "Building knowledge building communities: Consistency, contact and communication in the virtual classroom," Journal of Educational Computing Research, vol. 23, pp. 359-384, 2000.

[29] A. Young, "Structuring asynchronous discussions to incorporate learning principles in an online class. One professor's course analysis," Journal of Online Learning and Teaching, vol. 4, pp. 217-225, 2008.

[30] K. Swan, "Virtual interaction: Design factors affecting student satisfaction and perceived learning in asynchronous online courses," Distance education, vol. 22, pp. 306-331, 2001. http://dx.doi.org/10.1080/0158791010220208

[31] K. A. Meyer, "Face-to-face versus threaded discussions: The role of time and higher-order thinking," Journal of Asynchronous Learning Networks, vol. 7, pp. 55-65, 2003.

[32] J. Hewitt, "Toward an understanding of how threads die in asynchronous computer conferences," The journal of the learning sciences, vol. 14, pp. 567-589, 2005. http://dx.doi.org/10.1207/ s15327809j1s1404_4

[33] V. P. Dennen, "From message posting to learning dialogues: Factors affecting learner participation in asynchronous discussion," Distance Education, vol. 26, pp. 127-148, 2005. http://dx.doi.org/10.1080/01587910500081376

[34] G. M. Johnson, "Synchronous and asynchronous text-based CMC in educational contexts: A review of recent research," TechTrends, vol. 50, pp. 46-53, 2006. http://dx.doi.org/10.1007/ s11528-006-0046-9

[35] A. P. Rovai, "Facilitating online discussions effectively," The Internet and Higher Education, vol. 10, pp. 77-88, 2007. http://dx.doi.org/10.1016/j.iheduc.2006.10.001

\section{AUTHORS}

Mengmeng Cheng is with Institute of Education Technology, College of Education, Zhejiang University, Tian Mu Shan Rd.\#148, Hangzhou, Zhejiang, China, 310028 (e-mail: cmm.870524@163.com).

ChienYuan Su is a lecture working at Institute of Education Technology, College of Education, Zhejiang University, Tian Mu Shan Rd.\#148, Hangzhou, Zhejiang, China, 310028 (e-mail: bredysu@gmail.com).

Jianping Zhang is a professor working at Institute of Education Technology, College of Education, Zhejiang University, Tian Mu Shan Rd.\#148, Hangzhou, Zhejiang, China, 310028 (e-mail: 21zjp@vip.163.com).

Yuhui Yang is with Institute of Education Technology, College of Education, Zhejiang University, Tian Mu Shan Rd.\#148, Hangzhou, Zhejiang, China, 310028 (e-mail: zjuyyh@zju.edu.cn).

This work was supported by a grant from the National Social Science Foundation of China (BCA130018). Manuscript received 13 May 2015. Published as resubmitted by Jianping Zhang 13 September 2015. 